\title{
DAS BATALHAS IDENTITÁRIAS ÀS PRÁTICAS DE LIBERDADE: HISTÓRIAS DE VIDA DE UMA PROFESSORA NEGRA
}

\author{
Marluce Pereira da Silva \\ Carmen Brunelli de Moura" \\ Francisca Maria de Souza Ramos Lopes
}

Resumo: Neste artigo, analisa-se a produção de sentidos na autonarrativa de uma professora negra ao construir seus projetos identitários concernentes à trajetória escolar e profissional, aos arranjos afetivoconjugais face ao seu pertencimento racial. Define-se como questão norteadora da discussão: em que medida a docente assume posicionamentos discursivos que refletem a interação entre seus anseios pela liberdade individual e/ ou a segurança que a comunidade oferece? Utilizam-se como dispositivos analíticos as teorizações foucaultianas, articuladas a estudos étnico-raciais, identitários e noções da Análise do Discurso Francesa (AD). Concluiu-se que a docente, em seus roteiros autobiográficos, se muniu de estratégias que traduzem batalhas por ela travadas ao construir seus projetos identitários, à medida que institui uma história de vida traduzida por efeitos que contradizem discursos que a bistória reservou a negros/as.

Palavras-chave: Projetos identitários. Práticas de liberdade. Professora negra.

[...] a "identidade" é uma ideia inescapavelmente ambígua, uma faca de dois gumes. (Z. BAUMAN, 2005).

\section{INTRODUÇÃO}

As palavras de Bauman abalizam a ideia de que a identidade se dá por meio de um processo constante de experimentos infindáveis. A ambiguidade já na sua definição conduz efeitos de uma batalha, à medida que as práticas identitárias são vivenciadas de forma defensiva tanto por

\footnotetext{
* Professora da Universidade Federal da Paraíba. Dra. Em Linguística e Letras pela Universidade Estadual Paulista "Júlio de Mesquita Filho"(UNESP). Email: marlucepereira@uol.com.br.

** Professora do Departamento de Letras da Universidade Potiguar (UnP). Dra. Em Estudos da Linguagem pela Universidade Federal do Rio Grande do Norte (UFRN). Email: carmenbm@bol.com.br.

*** Professora Adjunta do Departamento de Letras da Universidade do Estado do Rio Grande do Norte (UERN). Dra. Em Estudos da Linguagem pela Universidade Federal do Rio Grande do Norte (UFRN). Email: francisca.1@bol.com.br.
} 
indivíduos que resistem aos ataques de grupos menores quanto por estes quando também se posicionam no contra-ataque a grupos maiores e mais ameaçadores. O grupo maior, por vezes, reconhece que há diferenças e identidades alternativas que podem afetar, comprometer e causar riscos a seus projetos identitários hegemônicos e isso pode representar uma ameaça à ordem, à segurança.

No entanto, como não há mais jogos de verdade definidos a priori nem comunidades ${ }^{1}$ integradoras ortodoxas, é preciso compreender que as identidades se constroem de forma distinta daquelas que eram cultivadas sob uma camisa de força para que se mantivessem as mesmas por um tempo indefinido. Atualmente, as batalhas travadas por práticas identitárias sintetizam a complexidade das relações sociais na modernidade liquefeita em que a vinculação entre identidade e diferença, entre similitude e alteridade estabelecem ações políticas (GILROY, 2007).

Neste artigo, partindo da compreensão de que a identidade é um campo de batalha que nos convoca a toda hora a defender e a refletir criticamente o que somos e o que desejamos, pretendemos problematizar que, na contemporaneidade, a identidade é um processo construído sem um forte sentimento de pertencimento ou estabilidade ou, como diz Bauman (2003), as pessoas podem se desfazer de uma identidade quando esta deixa de ser atraente, satisfatória ou apropriada para determinados fins e se ajustar a outras mais cambiantes, que anseiam por transformações contínuas.

Em vista disso, nosso propósito é analisar a produção de sentidos na narrativa de uma professora negra ao construir seus projetos identitários concernentes à trajetória escolar e profissional e aos arranjos afetivo-conjugais face ao seu pertencimento racial. Para tanto, definimos como questões norteadoras da análise: de que modo se constituem marcas identitárias em sequências discursivas que compõem a narrativa de vida de uma professora negra e que possibilitam sua transformação? Em que medida a docente assume posicionamentos discursivos que

\footnotetext{
${ }^{1}$ Para Bauman (2003), a comunidade implica em segurança, uniformidade, conservação, imposição, e na contemporaneidade esses valores já não têm tanta relevância, pois os discursos a respeito de novidades, transformações, escolhas e liberdades são parte da constituição das identidades dos sujeitos.
} 
refletem a interação entre seus anseios pela liberdade individual e/ou a segurança que a comunidade oferece?

Para abordar esses questionamentos, recorremos a noções como práticas de liberdade, jogos de verdade (FOUCAULT, 2004a), identidade (BAUMAN, 2005, DUBAR, 1997), articuladas a estudos étnico-raciais (BERQUÓ, 1988; MOUTINHO, 2004) e ainda a noções da Análise do Discurso Francesa (AD) como discurso, efeitos de sentido (ORLANDI, 2006; PÊCHEUX,1988).O fio condutor deste estudo é a análise da materialidade linguístico-discursiva das narrativas de uma professora negra, heterossexual, que constitui sua identidade a partir de jogos de verdade, nos quais podemos compreender uma história proveniente de discursos que possam ser compreendidos como falsos ou verdadeiros. A geração dos dados analisados neste artigo adveio de uma entrevista realizada por uma das pesquisadoras ${ }^{2}$ junto a uma professora negra da cidade de Assu/RN, que frequentava um curso de Formação Continuada, em nível de Especialização.

\section{OS CAMINHOS DA PESQUISA}

A contemporaneidade, considerando-a como uma atitude em que a ordem é pensar, sentir, agir e conduzir-se de outra maneira e de forma voluntária na atualidade, conforme as palavras de Michel Foucault (2004a), exige que deixemos o aconchego dos discursos tradicionais nos quais predominam verdades já concebidas e leis estabelecidas previamente em relação aos modos de fazer pesquisa e nos lancemos em busca de práticas que propiciem uma "[...] possibilidade aberta de falar" (FOUCAULT, 2004b, p. 25). É nesse contexto de fronteiras mais abertas que, como pesquisadoras, procuramos inscrever a nossa investigação na área da Linguística Aplicada (LA) que, dado o seu caráter transdisciplinar, (SIGNORINI, 1999; CELANI, 1992; MOITA LOPES, 2006, 2009), interage com práticas discursivas que atravessam as fronteiras dos estudos linguísticos, permitindo que questões pertinentes ao tema escolhido sejam pensadas no âmbito de pressupostos epistemológicos que concebem a língua "[...] a partir de um

\footnotetext{
${ }^{2} \mathrm{O}$ trabalho da pesquisadora e este estudo se inserem no projeto de pesquisa Discurso, Identidade e Memória junto ao programa de Pós-graduação em Estudos da Linguagem (PPGEL) da Universidade Federal do Rio Grande do Norte (UFRN).
} 
conceito múltiplo não unificado, produzido por percursos transdisciplinares de reflexão sobre as práticas focalizadas" (SIGNORINI, 1999, p. 64).

Áreas como Sociologia e Antropologia têm tradição nos estudos cujo objeto central são identidades sociais e culturais. No campo dos estudos linguísticos e, em especial, dos linguísticos aplicados, atualmente verificamos maior produção bibliográfica sobre a temática das identidades. Professores de diferentes instituições de ensino superior e de diversos programas de pós-graduação têm demonstrado preocupação em estudar e pesquisar a respeito da constituição discursiva de identidades em sala de aula e em outros contextos institucionais. Alguns direcionam o seu olhar para a relação entre algumas identidades e o desempenho discente no processo de ensino-aprendizagem; outros, para a relação entre identidades e o uso ou o processo de ensinoaprendizagem de línguas maternas ou estrangeiras; outros problematizam identidades profissionais, como é o caso dos pesquisadores que se preocupam com a formação docente. Nesse sentido, o interesse por este campo de pesquisa aplicado envolve a compreensão de que os espaços de conhecimento precisam ser ampliados, uma vez que, para compreender linguagem e vida social, é preciso transgredir certos jogos de verdade e adentrar terrenos um tanto desconhecidos.

Em meio a esses jogos, muitas vezes inter/indisciplinares, construídos entre fronteiras fluidas, heterogêneas e, por que não dizer, contraditórias, a pesquisa, assim como a linguagem, deve sempre ser compreendida como uma prática social, pois dessa maneira há possibilidade de romper com certas verdades, ressignificar outras e produzir novos discursos com outros sentidos que permitirão movimentos mais singulares em relação ao objeto de pesquisa. Assim, o caminho investigativo tomado tem como base a pesquisa interpretativista, por representar " [...] um foco de investigação diferente, revelador, portanto, de novas descobertas" (MOITA LOPES, 1996, p. 22) sobre as professoras, suas histórias e a constituição de suas identidades em meio a práticas de liberdade, compreendidas como a constituição de ações reflexivas e práticas do sujeito para a sua transformação (FOUCAULT, 2004a).

Para a realização desta pesquisa, os dados foram coletados por uma das pesquisadoras junto a quinze professoras negras de escolas 
públicas de Assu e Pendências, cidades do interior do Rio Grande do Norte, graduadas em Letras e Pedagogia e pós-graduandas de um curso de Especialização, oferecido pela Universidade do Estado do Rio Grande do Norte (UERN). A metodologia utilizada para a coleta dos dados envolveu alguns procedimentos etnográficos, concebidos por nós como práticas discursivas, e descritos como questionário, produção de histórias de vida escrita, rodas de conversa e entrevistas semiestruturadas.

A primeira prática, o questionário, aconteceu durante as aulas ministradas por uma das pesquisadoras no curso, uma vez que ela desejava saber como as professoras estavam vivenciando seu processo de desenvolvimento profissional. Na parte de identificação das professoras foi inserido o item cor, conforme categorias ${ }^{3}$ utilizadas pelo Instituto Brasileiro de Geografia e Estatística (IBGE). De um universo de 65 professores/as inscritos/as e distribuídos/as em duas turmas, quatorze professoras se identificaram como pretas ou pardas, e foi a estas que a pesquisadora revelou sua intenção de realizar uma pesquisa e seu interesse pela temática acerca do pertencimento étnico-racial. Após esta primeira conversa, treze professoras decidiram participar da pesquisa e mais dois professores também procuraram se inserir no grupo, totalizando assim, quinze docentes.

A seguir, a professora pesquisadora indagou sobre a disponibilidade dos docentes em se tornarem protagonistas do estudo. Foi neste momento que as/os professoras/es revelaram em seus discursos - discurso aqui tomado como efeito de sentido entre os sujeitos, afetados pelas práticas sociais (ORLANDI, 2006) - e atitudes certo receio, dúvida, desconfiança, em relação a sua exposição em um trabalho a ser divulgado no meio científico. Assim, Prontamente, elas/eles foram informadas/os acerca de procedimentos éticos a serem adotados na pesquisa, como a preservação de sua identificação pessoal, respeito aos episódios relatados, acesso aos dados antes de sua publicação. Essas informações foram suficientes para que neste grupo de professoras e professores dez professoras aceitassem colaborar com a proposta. Isso levou a outro procedimento da metodologia.

A segunda prática discursiva do processo investigativo seguiu com a produção de histórias de vida escritas cujo roteiro deveria evidenciar

${ }^{3}$ O IBGE, a partir do Censo de 1991, inclui as categorias branco, preto, pardo, amarelo e indígena.

SILVA; MOURA; LOPES - Das batalhas identitárias às práticas de liberdade... 
situações cotidianas atreladas ao pertencimento racial, relatando em que medida as professoras vivenciaram episódios que apontassem práticas de racismo e como essas práticas tiveram implicações no processo de constituição de suas identidades. Nessas histórias havia discursos de verdade, naturalizados nas práticas sociais, de que o negro possui marcas identitárias que o apontam como inferior, incompetente e mau-caráter. Identidade subjugada por efeitos de sentidos de grupos dominantes e que aparecem evidenciados em enunciados da professora Constância ${ }^{4}$, em sua autonarrativa:

[...] estudei com muitas dificuldades, no meio dos brancos, muitas colegas não aceitavam fazer os trabalhos de grupo comigo. [...] fui discriminada aos nove anos de idade por uma professora racista, xingou-me, chamou-me de negra e me retirou da sala, pôs a turma para gritar: negra na minha sala de aula, não tem direito a estudar.

As temáticas que permearam as narrativas das professoras produziam sentidos relacionados: ao lugar de origem, às brincadeiras de infância, a doenças, à perda de familiares, à aprovação no vestibular, ao primeiro emprego, à primeira menstruação, ao primeiro namorado, à pobreza vivenciada, etc. No entanto, para questões vinculadas ao seu pertencimento racial, pouco foi revelado. As dificuldades presumivelmente enfrentadas não pareciam produzir efeitos de sentidos tão presentes em práticas discursivas circulantes nas diferentes esferas sociais. As poucas situações narradas diziam respeito unicamente à não aceitação de algumas famílias a arranjos conjugais afetivos inter-raciais.

O silenciamento das professoras em face de sua condição de mulher e negra nos inquietou e ao mesmo tempo nos instigou na elaboração de uma terceira prática da pesquisa: as rodas de conversa. Para incitar as professoras a falarem, fizemos a leitura do artigo $A$ Cinderela Negra (FRY, 1995) que aborda a ocorrência de práticas racistas vivenciadas, na época, por Ana Flávia, filha do então governador do Espírito Santo, Albuíno Azeredo. Também foi distribuído e lido o texto

\footnotetext{
${ }^{4}$ Os nomes das professoras são fictícios.
} 
jornalístico "Mulher é presa por racismo", veiculado pelo jornal Diário de Natal, em março de 2007. O artigo noticiava um acontecimento que revelava práticas discriminatórias de que se proveu uma funcionária pública ao se dirigir ao guarda de uma instituição hospitalar, agredindo-o verbalmente. A utilização de tal estratégia seria com o propósito de provocar reflexões nas professoras em relação à temática, e poderiam produzir novos efeitos de sentidos em suas narrativas.

O emprego das rodas de conversa como recurso metodológico pressupunha maior informalidade, interação, trocas, flexibilidade no tempo de fala de cada professora. Assim, a opção por este procedimento resultou da concepção de ser a conversa uma prática discursiva na qual as professoras passavam a produzir outros sentidos e a se posicionar com mais intensidade em sala de aula, como a professora Marreiro quando enuncia:

[...] eu já fui vítima de racismo. De preconceito por causa da minha cor. Hoje nem tanto, mas há uns vinte anos atrás eu sofri bastante com isso, né?

Ou ainda nos enunciados da professora Constância:

[...] as dificuldades dos negros são grandes. Porque quando a gente chega na frente dos bancos, nas vitrines dos grandes centros comerciais, a gente se depara com as criaturas brancas, de boa aparência.

Mas, algo nos chamou a atenção nessas conversas. Havia uma professora em cujos discursos evidenciava-se outro modo de ser mulher e negra. Era Sol, que se mostrava um tanto intransigente em dar depoimentos, escrever histórias. O que faríamos então? Como abrir espaço para práticas que propiciassem a Sol novas práticas de liberdade?

Foi então que passamos a nos utilizar da quarta prática discursiva: a entrevista, que permite uma compreensão do processo de construção de identidades do sujeito, uma vez que os sentidos se constroem em uma interação em que entrevistado e entrevistador marcam suas posições nas 
práticas socais. A entrevista de Sol foi realizada na residência de uma das pesquisadoras, conforme solicitação da docente. Mas, mesmo estando no ambiente por ela sugerido, Sol não permitiu que a entrevista fosse gravada. Muito foi perdido de sua narrativa, mas em dado momento Sol consentiu que a pesquisadora anotasse ou digitasse sua narrativa, o que resultou ao final num texto escrito por ambas. Assim, é nos mecanismos linguístico-discursivos da entrevista de Sol que passaremos a reconhecer de que forma a professora afiança suas identidades ao entrar em jogos de verdade e na construção de seu projeto identitário e sair deles transformada.

\section{PRÁTICAS DE LIBERDADE: O OUTRO LADO DAS RELAÇÕES DE PODER}

Problematizar as identidades a partir de práticas de liberdade implica pensar a constituição do sujeito de uma forma diferente daquela em que "corpos dóceis"5 eram subjugados por poderes que disciplinavam e assujeitavam. A ideia de um poder disciplinador, violento, dominador, soberano que se utiliza de tecnologias que "[...] determinam a conduta dos indivíduos, os submetem a certos fins ou dominação" (FOUCAULT, 1990, p. 48), objetivando-os a partir da imposição de marcadores sociais de classe, gênero, raça, etnia, parece ceder lugar a outra concepção de poder inserida em outros jogos de verdade, outros sujeitos que falam sob outros pontos de vista a fim de obter outros efeitos de sentido.

O poder, agora, é uma relação entre sujeitos e se dá sob formas diferentes, como entre os membros de uma família, em uma relação pedagógica ou no corpo político, pois não é possível imaginar uma sociedade sem relações de poder. Os sujeitos sabem que precisam desses relacionamentos para definir a si mesmos e suas identidades, para o seu bem-estar e pela coesão e lógica do seu próprio modo de ser. Essa relação com o outro perpassa todo o depoimento de Sol, como podemos notar desde o início, quando ela começa se relacionar com a pesquisadora e enuncia:

\footnotetext{
${ }^{5}$ Para Michel Foucault (2003), os indivíduos entram em uma maquinaria de poder que os disciplina e os torna submissos, aumentando a utilização de seus corpos e limitando práticas de liberdade.
} 
Meu nome é Sol. Tenho 38 anos, vou falar um pouco de minha história porque achei você muito bacana [...]

Esta ascese continua na relação com os colegas de escola e de trabalho, pais, tias e avós, namorados. Enfim, a relação intersubjetiva faz parte dos inúmeros jogos de verdade, compreendidos como um conjunto de regras que produzem discursos e constituem identidades sempre em transformação (FOUCAULT, 2004a). Como afirma Dubar (1997),

[...] identidade não é nada mais que o resultado simultaneamente estável e provisório, individual e coletivo, biográfico e estrutural, dos diversos processos de socialização que, em conjunto, constroem os indivíduos e definem as instituições.(DUBAR, 1997, p. 105).

Essa concepção de identidade construída pelo olhar sociológico de Dubar descarta a ideia de que o social unifica os processos identitários. A socialização da qual o estudioso fala é heterogênea, complexa, instável e uma permanente batalha na qual os sujeitos se embatem entre a segurança e a liberdade. Assim parece se evidenciar a construção das identidades de Sol. Algumas dessas identidades corroboram verdades que fazem parte do senso comum, ou seja, de que Sol deve se privar de certos ambientes e relacionamentos para que não sofra os males trazidos por marcas identitárias da negritude. A narrativa de Sol evidencia efeitos de sentido em torno do papel protetor da mãe, avó e tias, traduzidos por práticas discursivas ante a condição afetiva sexual da mulher negra:

[elas diziam que] não desse atenção aos meninos brancos pois eles só iriam querer se aproveitar de mim, desgraçar minha vida e eu ia ser falada. Diziam também que branco com negro não dava certo. Que as famílias deles não iriam querer. 
Em sua narrativa, a docente remete à manifestação de animosidade que atravessa os sentidos de práticas discursivas produzidas e circulantes no seio familiar, apontando a condição de inferioridade da mulher negra em relação ao homem branco. Esse, em algumas situações, conforme é revelado pelos membros da família negra, passa a explorar a sua condição de superioridade no âmbito dos relacionamentos inter-raciais. Relação que Moutinho (2004) analisa com olhar de suspeição, uma vez que:

[...] no mesmo país que valoriza em diferentes âmbitos a mestiçagem e a "mistura", parece existir um tabu contra os casamentos "inter-raciais". Em um nível, o desejo e o sexo "heterocrômicos" são "desejáveis"; em outro nível, ao menos o casamento (e por que não dizer também o sexo e o desejo) aparecem como "indesejáveis" (MOUTINHO, 2004, p. 344, grifos da autora).

Essa preocupação da autora é traduzida no temor que afeta as famílias das mulheres negras e evidenciada nas marcas linguísticas aproveitar, desgraçar, falada, na narrativa de Sol, que articulam efeitos de uma preocupação da família na constituição de sua identidade, uma vez que é na e pela interação com outros sujeitos que um processo de rotulagem pode ser desencadeado e a pertença a determinado grupo fica prejudicado.

Nessa relação com os meninos brancos, evidenciava-se a construção identitária de mulher e, aliado a isso, discursos de verdade preconceituosos, uma vez que a família dizia que o casamento entre raças não daria certo e justificava que o motivo era o fato de a família branca não admitir essa união. Mas, não era só isso. Os enunciados de Sol, especificamente a sequência:

[...], pois eles só iriam querer se aproveitar de mim, desgraçar minha vida e eu ia ser falada [...], 
apresentam-se atravessados por práticas discursivas presentificadas em outros momentos históricos da sociedade brasileira. No Brasil Colônia, os senhores de engenho faziam uso da sua posição social e econômica privilegiada para saciarem os seus desejos sexuais com as escravas e os escravos. Nessa narrativa, observamos a repetição de discursos que expressam sentidos em que a cor negra é revestida de um papel crucial no mercado erótico afetivo, em práticas discursivas cujos sentidos determinam que a prostituição pode ser um dos lugares destinados à mulher negra.

Pesquisas realizadas por Berquó (1998), baseadas em dados demográficos, constataram que o significativo percentual de relações exogâmicas são praticadas por homens negros com mulheres brancas. Tal fato parece ter como corolário a mobilidade social e espacial do homem negro, tanto entre seus grupos sociais como entre outros grupos. De acordo com Moutinho (2004), a valorização do homem negro, em detrimento da mulher negra no mercado erótico afetivo, converge também para os resultados apontados na pesquisa de Berquó acerca da solidão da mulher negra. Essa, ao contrário do homem negro, enfrenta dificuldades para constituir arranjos familiares tanto com homens de sua raça quanto de outros grupos. A esse respeito, Moutinho (2004) comenta:

[...] em vários casos, antes de ser um atributo que requer compensações, a "cor negra", em si, funciona como um forte elemento de atração, dado os conteúdos eróticos (entre outros) que lhe são atribuídos. Falas que concedem, por si, um lugar de prestígio ao homem "negro" na disputa do mercado eróticoafetivo. (MOUTINHO, 2004, p. 344).

Esse jogo de forças afeta a mobilidade da mulher negra e o seu direito de escolha, conforme enuncia Degler (apud MOUTINHO, 2004, p. 243) ao afirmar que "a mulher não se casa com quem ela quer, mas com quem quer ela”. No âmbito de mobilidade social e espacial, vivenciado bem mais pelo homem negro do que pela mulher negra, pode-se incluir a questão do clareamento (BERQUÓ, 1988) ou 
branqueamento $^{6}$ (SILVA, 1987) dos filhos em vista da incorporação de alguns atributos de prestígio social da mãe. Tal prática foi instaurada desde os últimos séculos no nosso país. A busca pelas características peculiares do grupo branco tem origem na sociedade colonial e escravista perpassando para o imaginário e as práticas discursivas dentro da sociedade brasileira.

Mas, não nos esqueçamos de que a faca tem dois gumes e em um destes há outras verdades, diferentes das anteriores e nas quais as práticas de liberdade dizem a Sol como se conduzir de outra maneira, como ser mais livre em meio a práticas discriminatórias e a discursos que implicam a adesão de uma identidade padrão. Por isso, na sociedade contemporânea, onde o poder não é mais vertical, mas relacional, é possível entrever exercícios de liberdade entre as relações de poder. É em busca desses interstícios de liberdade que nos voltamos para os discursos de Sol, principalmente quando, durante a entrevista, ela vai se desnudando e evidenciando transformações, recriações de suas identidades em meio aos discursos presentes da própria narrativa. $\mathrm{Na}$ perspectiva de Foucault, esse posicionamento de Sol é incitado pelo próprio poder, ou seja, pela atitude tomada por ela, pelo governo de si face às estruturas sociais. $O$ caso aqui não é rejeitar o poder, mas conviver com ele, e os sujeitos devem perceber-se como autodeterminantes e capazes de desafiar e resistir às práticas de dominação na contemporaneidade.

Embora a relação intersubjetiva seja necessária na constituição das identidades, esses vínculos subjetivos passam, muitas vezes, a ser ambivalentes, pois todos são dotados de igual liberdade para fazer escolhas, mas uns tentam determinar a conduta dos outros e é isso que vai tornar o jogo das práticas identitárias mais aberto, fascinante e atraente. Mas, como isso se dá no jogo em que Sol se dispõe a jogar? De que modo a professora percebe que há inúmeros jogos e que é possível mudar algumas regras desses jogos discursivos que tentam definir suas marcas de identidade?

\footnotetext{
${ }^{6} \mathrm{O}$ branqueamento ou clareamento é compreendido como normas, valores, comportamentos, relacionados aos grupos de brancos, que são incorporados por grupos não brancos cujo objetivo é constituir uma identidade geralmente associada às comunidades integradoras que promovem certa uniformidade na conduta dos sujeitos.
} 
Nesse jogo, Sol não pode fugir à entrada no campo de batalha e sabe que é preciso lançar mão de sua faca da identidade contra as pressões sociais eresistir às estruturas de dominação. É no vocábulo "resistir", ou "resistência" que parece estar o cerne da virada no pensamento foucaultiano ao conduzir suas duas últimas obras ${ }^{7}$ em relação à definição dos espaços de liberdade nos quais o sujeito desponta como um criador de si mesmo e transformador do mundo no qual vive. Mas, é preciso esclarecer que esses espaços são paradoxais, uma vez que poder, resistência e liberdade não se opõem. Ambos se completam, ou seja, um é condição do outro, pois como diz Foucault, "nas relações de poder há necessariamente possibilidade de resistência, pois se não houvesse possibilidade de resistência [...] não haveria de forma alguma relações de poder" (FOUCAULT, 2004a, p. 277). E, continua: "Se há relações de poder em todo o campo social, é porque há liberdade por todo lado" (FOUCAULT, 2004a, p. 277) e isso implica uma relação do sujeito consigo mesmo, ou seja, uma relação ética, como também relações complexas com o outro.

Assim, os jogos de verdade nos quais Sol se dispõe a jogar propiciam a ela discursos que rompem com a relação estabelecida entre o sujeito e as verdades em termos de práticas coercitivas. Os jogos de verdade vão conduzir Sol a ser sujeito de suas práticas discursivas, de uma história, compreendida como uma prática ascética, uma prática de autoformação em que ela, a partir de um exercício de si sobre si mesma, por conta própria ou com a ajuda do pesquisador e outras pessoas, tenta desenvolver ou transformar a si para chegar a outro modo de ser. É a produção de identidades se fazendo em meio a discursos de verdades e inúmeros processos de autoformação, que permitirão ao sujeito, nos jogos de poder, jogar com o mínimo possível de dominação.

A ideia de ambiguidade, representada pela metáfora - faca de dois gumes - atribuída por Bauman à identidade, nos auxiliará no nosso propósito de analisar a produção de sentidos que atravessa os projetos identitários da docente. A metáfora abarca os diferentes sentidos que conformam as trajetórias de Sol na medida em que é evidenciada uma batalha constante entre poder e liberdade na construção de suas

\footnotetext{
${ }^{7}$ Estamos nos referindo às últimas publicações: História da sexualidade II: o uso dos prazeres e História da sexualidade III: o cuidado de si, ambas publicadas em 1984, ano de sua morte.
}

SILVA; MOURA; LOPES - Das batalhas identitárias às práticas de liberdade... 
identidades. Nessa luta, Sol enfrenta valores imprescindíveis a sua existência que se dão na tensão entre "liberdade de escolha e segurança oferecida pelo pertencimento" (BAUMAN, 2005, p. 84). Os dois valores apontados pelo autor - liberdade e segurança - são necessariamente contraditórios, difíceis de conciliar, mas, paradoxalmente, em dado momento, eles podem figurar dispostos lado a lado. Como diz Bauman (2003, p. 20), a "[...] identidade brota entre os túmulos das comunidades" e "[...] uma vida dedicada à procura da identidade é cheia de som e de fúria” (BAUMAN, 2003, p. 21).

É nesse entrelugar no qual a comunidade entra em crise que as identidades são inventadas, transformadas, uma vez que elas são construídas em um processo sem fim e sempre incompleto. É nesse processo contínuo que vamos encontrar Sol tentando se desfazer de identidades oferecidas pela comunidade e se aventurar em práticas de liberdade:

[...] comecei a demonstrar gostar muito de estudar, meus pais mesmo analfabetos diziam que se as pessoas estudassem dariam pra gente, arranjavam emprego e não seriam tão pobres como eles. Aí comecei a entender que meu caminho seria mesmo estudar.

É nesse momento da narrativa que nosso olhar deixa o gume da faca que oferece segurança a Sol e no qual se propagam modelos identitários que servem de referência para a ocultação de práticas étnicoraciais como desigualdade, deficiência, racismo, exclusão, enfim, representações que evidenciam sentidos negativos de ser negro e negra, e passa a problematizar o outro gume. Gume que vai permitir a Sol não apenas aprender a lidar com mestria com essas representações, como também a construir outra história que evidenciará a instituição de estratégias com outros sujeitos a partir de sua liberdade individual.

Nesse conflito, problematizamos estratégias discursivas imprescindíveis para a assunção de seu pertencimento de modo a permitir que a sua transformação escape ao intento de não ter suas diferenças invisibilizadas pelos discursos de verdade de comunidades que lhe propõem segurança. Mas, que estratégias são utilizadas por Sol como 
lutas defensivas em face de discursos que anulam sujeitos que reivindicam outras histórias, outras identidades? Em que medida as práticas de liberdade propiciam a Sol brandir a faca contra as pressões sociais?

\section{BATALHAS TRAVADAS: PRÁTICAS EXPERIENCIADAS}

Embora uma análise da narrativa de Sol já venha sendo ensaiada no texto, é neste momento que revelamos nosso interesse maior em investigar a produção de sentidos que instauram os projetos identitários da professora, concernentes a diferentes episódios por ela vivenciados. Para isso, escolhemos alguns mecanismos discursivos que, na autonarrativa de Sol, parecem traduzir efeitos de sentido que apontam para momentos de sua transformação ao travar embates contrariando práticas discursivas em relação ao ser negro/a. As práticas de liberdade serão traduzidas em dois dispositivos analíticos: trajetória escolar e profissional e "arranjos" afetivo-conjugais.

\subsection{Trajetórias escolar e profissional}

A instituição escolar representa os dois gumes da faca. Um que oferece o máximo de segurança, aconchego e conforto e outro que está repleto de perigos, pouco confiável e com múltiplas pertenças. É nesse segundo gume, com uma "proliferação inédita de sugestões tentadoras e ofertas de orientação atraentes" (BAUMAN, 2009, p. 116), que vamos encontrar nos mecanismos discursivos da narrativa de Sol evidências de uma luta identitária. Sol começava a não concordar com uma identidade cuja imagem lhe é atribuída pelo outro e que implica em isolamento, discriminação, solidão, conforme descrito por ela para uma fase de sua vida: "No começo eu só tinha uma coleguinha que era bem branquinha. As outras nem ligavam para mim. Uma vez a professora me chamou de negra e me empurrou." Ao contrário, na tentativa de construir um outro projeto identitário, Sol passava a questionar os jogos de verdade que constituíam esse projeto, exercendo a liberdade, ou seja, reagindo contra certas práticas.

E como ela fazia isso? Sol recorria aos estudos e se afastava de uma história que fora construída para ela e não por ela. $\mathrm{O}$ seguinte 
trecho de sua narrativa parece traduzir efeitos de sentido presentes nas práticas de liberdade em que Sol se insere: "Fui sempre me destacando no colégio, comecei a ser convidada para apresentar poesias, participar de tudo que a escola fazia porque diziam que eu era inteligente e sabia ler bem". As expressões destacando, convidada e participar sustentam uma identidade diferente daquela do início de sua escolaridade, pois agora sua cor parecia não interferir negativamente em sua mobilidade social, nem fazer diferença, pois o que se sobressaía era sua habilidade em saber ler, destacando-a das outras crianças da escola.

$\mathrm{Na}$ autonarrativa de Sol são reveladas práticas discriminatórias que não se limitam apenas à etapa inicial de sua trajetória estudantil. Além disso, Sol assinala algumas situações também vivenciadas na época em que cursava Universidade:

[...] quando os colegas diziam coisas do tipo: "isso é coisa de negro", "só sendo negro mesmo", "negro é bicho safado", etc. se eu estivesse presente diziam: desculpe Solzinha, não é com você. Você é uma negra boa, tem a alma limpa. Também você é diferente, faz Faculdade, é pretinha/mas é gente fina, inteligente. Ouvi muitas coisas parecidas com essa. Ficava sempre triste, magoada.

As marcas linguísticas negra boa, alma limpa, diferente, gente fina evidenciam efeitos de sentido de práticas discriminatórias que são instauradas a partir de uma fronteira entre ser negro e ser branco. Esse jogo discursivo evidencia uma política geral de verdades e faz com que os colegas de faculdade de Sol, sujeitos que se colocam naquela situação como encarregados de dizer o que funciona como verdade, sancionem determinados sentidos que servem como parâmetro para a constituição das identidades de uns e de outros não. Em outras palavras, o que faz de Sol uma negra "diferente"? Seria o fato de fazer faculdade, de ser colega de brancos, de ser inteligente? Que sentidos estavam implícitos no marcador linguísticomas quando suas colegas diziam que ela é pretinha, mas é gente fina?

É exatamente em relação a essa discursividade naturalizada de coitadinha e de submissão que Sol precisava reagir. Ela precisava limitar 
seus efeitos que, embora não pudessem ser avaliados como bons ou maus, eram perigosos, de forma que seria preciso que Sol refletisse sobre a maneira de entrar nessa batalha e dela sair fortalecida. $O$ caminho encontrado por Sol foi, mais uma vez, os estudos. Era preciso que Sol voltasse a atenção para si mesma, e é isso que vamos descobrir em sua narrativa quando ela enuncia:

[...] cada vez mais eu estudava. Tinha que ser se não a melhor, mas estar entre osmelhores. Eu não podia ser somente boa. Eu tinha que ser ótima. Isso tendo que competir com pessoas que na sua maioria não trabalhavam, viviam somente para estudar, pois eram ricos.

É fácil perceber a luta empreendida por Sol em discursos que evidenciam sua insistente batalha. Aquela identidade que as colegas construíram para ela era deixada de lado e outra tomava seu lugar. Era uma identidade construída em meio a práticas de liberdade nas quais Sol refletia acerca de sua condição de mulher negra e pobre. Para isso, Sol precisava descobrir as verdades, ser esclarecida a respeito delas e, por fim, tomar essas verdades para si e enunciá-las como suas. Ao fazer isso, a professora poderia lutar de forma menos desigual com outros sujeitos que, muitas vezes, tentavam impor-lhe uma identidade sem se preocupar com o fato de as identidades serem heterogêneas e instituídas em um permanente processo. Em vista desse processo, a identidade de Sol já se diferenciava de seus colegas, pois ela trabalhava e estudava, o que produzia processos identitários que refletiam práticas associadas a Sol professora e a Sol aluna. Mesmo assim, se quisesse conviver com os brancos não era suficiente ter vencido as suas limitações e ter conseguido ingressar em uma Universidade pública. Naquele momento, sua forma de resistir, de se inscrever numa ordem de discursos da instituição escolar, era procurando ser a melhor, a mais estudiosa.

Em outra passagem de sua narrativa, Sol descreve um fato que marcou sua vida profissional. Ela conta que se submeteu a um concurso para professor em sua cidade, passou, mas foi bumilhada pela diretora, que, 
[...] botou todas as dificuldades para me convocar. Só chamou porque eu tive uma colocação das melhores. [...] Percebia que os olhares dela eram de discriminação, não engolia o fato de eu ser uma negra, muito pobre e ter sido aprovada num concurso público de muita seriedade.

Há no enunciado da diretora sentidos traduzidos por práticas que exprimem ser o negro intelectualmente frágil, esteticamente feio e de caráter duvidoso (SANTOS, 2003), ou seja, o fato de uma negra ter conseguido aprovação em um concurso público pode contrariar o interesse do grupo maior de qual fala Bauman (2003). Isso a levou a ter de trabalhar em uma escola da zona rural, muito longe de sua residência, o que motivava ter de acordar às quatro horas da manhã, assumir aulas nos turnos matutino e vespertino e ganhar metade do salário.

Como alguns sujeitos, nas práticas sociais, podem ter um desejo enorme de dominar a conduta do outro e não deixar espaço para sua transformação, uma outra atitude pode ser entrevista nas práticas entre sujeitos e que propicia condutas para a autotransformação. Este é o caso do diretor da escola rural, que percebe as humilhações da professora e vai em seu auxílio nesta luta com a diretora. Sol diz:

O diretor da escola foi quem lutou por isso quando soube de minha carga horária. Conversou comigo, mostrou que não estava certo. Eu com um expediente completo só ganhar pela metade. Eu disse a ele que sabia, mas tinha medo de ficar desempregada. Nessa época ele mostrou que eu era concursada e tinha direito. Assumimos essa briga juntos e eu consegui o aumento de minha carga horária. O que na época melhorou muito meu salário e eu que já ajudava minha família financeiramente passei a ajudar muito mais.

As expressões lutou, direito e briga produzem sentidos que reafirmam o que denominamos prática ascética, em que Sol assume um outro modo de ser, um outro modo de se conduzir e, portanto, uma outra identidade. Sol se distancia daquela identidade negra, frágil, incapacitada intelectualmente, construída pelo discurso da diretora, e 
passa a entrever no discurso otimista, guerreiro do diretor, que pode haver possibilidades diferentes de construir uma outra identidade em meio aos outros jogos de verdade. O diretor conversa, mostra uma outra regra do jogo na qual o discurso evidencia verdades das quais Sol precisa se equipar, ou seja, a diretora foi injusta e depois ela era uma professora concursada que deveria defender seus direitos. Essa relação intersubjetiva propiciou transformações na vida de Sol que se refletiram em seus projetos identitários. Uma identidade diferente, por meio de posições de quem assume também essa batalha e dela sai vitoriosa, como por exemplo, melhoria em seu salário e, consequentemente, melhoria na vida de sua família, pois ela passou "a ajudar muito mais".

\subsection{Arranjos afetivo-conjugais}

O tema dos arranjos afetivo-conjugais esteve muito presente na narrativa de Sol, que enfrentou práticas discriminatórias, como outras mulheres negras, resultantes de suas escolhas relacionadas aos afetos e à sexualidade. Algumas passagens narradas atraíram nossa atenção e, aos poucos, pudemos constatar que a questão relacionada aos afetos e à sexualidade recebeu destaque na construção discursiva das identidades da professora.

Ao namorar um rapaz branco, Sol julgou que havia algo errado em sua relação, pois ele se negou a contar à família sua condição de namorada. Como, muitas vezes, certas atitudes podem revelar mais para alguns que a utilização das já institucionalizadas práticas discriminatórias, a explicação dada por Sol a esse fato parece ser suficiente para a compreensão dessa afirmação:

No início não disse que éramos namorados. Perguntei por quê. Depois de muito enrolar, disse-me que ninguém da casa dele nunca tinha namorado uma pessoa de pele escura e preferia que eles primeiro vissem como eu era bacana, pra depois dizer que namorávamos. Aí me revelei.

Nessa relação com o outro, poderíamos depreender dos enunciados efeitos de uma estratégia quase anônima de dominação do 
namorado sobre Sol. Mas, ao contrário. Em conformidade com esta estratégia, surgem práticas de liberdade que "não são algo que se possua ou que pertença a alguém por natureza" (RAJCHMAN, 1993, p. 136), mas no discurso de Sol se evidenciam exercícios dessas práticas quando a professora enuncia que havia perguntado o porquê de ele não dizer à família sobre sua condição de namorada. Ao saber que poderia exercêlas, o enunciado Ai me revelei sugere outro projeto identitário, diferente daquele construído pela comunidade integradora, cujos discursos de verdade marcam com nitidez os lugares dos de dentro e dos de fora. Em outras palavras, as comunidades integradoras, conforme define Bauman (2009), tentam a todo custo manter tudo nos seus lugares e assim, evitar que "[...] os de dentro quebrem as normas e afrouxem os laços da rotina" (BAUMAN, 2009, p. 113) para aqueles que estão fora da comunidade.

No entanto, Sol não se identifica com essa imposição de rotinas, preservação e conservação de condutas, e tenta se equipar de discursos de outras práticas de liberdade, evidenciadas em seu enunciado que traduz a relação com o namorado:

Disse-lhe que ou ele me levava lá na próxima semana (eles moravam numa outra comunidade) e me apresentava como sua namorada ou tudo estava acabado.

Embora ele pareça negar a Sol o direito de escolha da identidade, pois seu discurso sugere que a relação com uma negra vai trazer-lhe problemas familiares, uma vez que vivemos em uma sociedade em que os valores e as regras são brancos, suas verdades vão funcionar como uma maneira de Sol constituir a si mesma.

Ou ele me levava lá [...] ou tudo estava acabado.

Esse enunciado sugere, pelas marcas linguísticas ou [...] ou, a ideia de exclusão, ou melhor, Sol dá ao namorado o direito de fazer escolhas como a ela tem sido dado em outras relações sociais. Mais uma vez Sol se constitui a partir do outro e desconstrói um discurso de branqueamento, muitas vezes registrados em amostras estatísticas. 
Essa é a ideia que desejamos imprimir à narrativa de Sol, tomada como uma técnica de desvelamento do eu, uma espécie de confissão em que não há uma renúncia do eu, como nas práticas cristãs, mas a constituição de um outro eu por meio de uma ascese. Esta técnica de verbalização constitui uma prática de liberdade à medida que o sujeito confessante se ocupa de si mesmo ao entrar nesses novos jogos de verdade $\mathrm{e}$ deles sair transformado. É uma atividade discursiva em que há uma afirmação do eu e da identidade, uma vez que envolve procedimentos de individualização contemporâneos que ligam os sujeitos entre si na afirmação de suas identidades.

Essa ligação aos outros nessa prática de autoconhecimento é uma relação muito complexa, uma vez que ainda se tem a ideia de que o outro se constitui em uma agência de dominação que obriga o sujeito a confessar suas verdades a fim de que, ao arrepender-se de suas faltas, seja absolvido. $\mathrm{Na}$ contemporaneidade, a relação com o outro implica em liberdade, pois ele será imprescindível para o acesso ao eu e aos jogos de verdade. É a partir da relação com o outro que a relação consigo começa a derivar. No caso de Sol, a pesquisadora é esse outro que obriga a confessante a ser livre à medida que propicia um deciframento de si assim como escolhas estratégicas que visam deixar abertos os espaços para que Sol busque as verdades mais significativas em sua vida, construídas em relações sociais.

Em outra parte de sua narrativa, percebemos nos discursos de Sol a recorrência a práticas que associam a imagem da mulher negra a uma sexualidade exacerbada. E dessa prática de liberdade que a professora se utiliza para tentar mostrar ou reafirmar, de acordo com os discursos de verdade que se apresentam na sociedade, características físicas e estéticas que podem homologar a sexualidade atribuída à mulher negra, no exercício do poder, ante os arranjos do mercado matrimonial. Ela enuncia:

[...] fiquei mocinha vieram os paqueras. Eu era muito bonita, bem feita. Mas os meninos me chamavam de negra gostosa, negra boa.

A partir da utilização do adjetivo bonita e da expressão bem feita é possível construir sentidos de que a professora, ao afirmar sua assunção à condição de negra, constitui identidades na tentativa de querer 
patentear a sua igualdade ou superioridade, pelo uso do advérbio de intensidade muito, no que diz respeito a padrões de beleza ideal. A sequência discursiva: "mas os meninos me chamavam de negra gostosa" podem revelar efeitos de sentido que reafirmam a positividade dos atributos de beleza, por ela realçados, pois vivificam a questão da sexualidade ou sensualidade que perpassam seus discursos, uma vez que ela era a gostosa. Isso parece se reafirmar em outra parte de sua narrativa quando Sol discorre ainda sobre suas relações afetivas com homens brancos e negros.

Moutinho (2004) observa que o "mercado afetivo" é, reconhecidamente, um dos espaços mais preconceituosos das relações raciais brasileiras. Essas também se constituem em dispositivos responsáveis pela construção das identidades pessoais e sociais fluentes de representações que permitem aos sujeitos se identificarem e se posicionarem, ou não, perante determinadas definições fornecidas pelos discursos de verdade que circulam na sociedade, como podemos perceber neste enunciado de Sol:

Naquele tempo não conhecia quase nenhum rapaz negro e quando conhecia eles não davam atenção a mulher negra. Também não sei se naquela época eu queria namorar um negro. Talvez eu mesmo não quisesse, por isso não apareciam. Às vezes, quando eu dizia as minhas irmãs que queria namorar um negro elas riam e diziam Deus me livre. Se me virem agarrada com um negro é uma briga. Eu ria e dizia que não concordava. Não pensava assim, mas hoje não sei se não pensava. Terminei casando com um branco. Graças a Deus que estudei se não, não sei o que seria de mim, talvez nem um casamento tivesse conseguido.

Destacamos, nesta sequência discursiva, efeitos que produzem uma identidade que se desfaz de verdades naturalizadas de que a negra é a escolhida. Sol evidencia efeitos contrários ao enunciar: "[...] não sei se naquela época eu queria namorar um negro". Nesse enunciado se desfazem os efeitos materializados no ditado popular "branca pra casar, negra pra trabalhar, mulata pra fornicar". Nessa sequência revelamos, também, que o enunciado "Terminei me casando com um homem 
branco", sugere que o verbo terminar, empregado no pretérito, produz sentidos que revelam possibilidade da mulher negra para a seletividade de seu cônjuge, pois, segundo a docente, não havia nada decidido em sua vida quanto ao casamento com um negro.

Embora Sol discorra com certa mestria sobre suas relações com homens brancos e que terminou "casando com um branco", o que mais nos chamou a atenção foi o fato de que acima de qualquer casamento com negro ou branco, havia algo mais precioso para Sol: a mobilidade social foi conseguida pela formação acadêmica. Ela revela:

Graças a Deus que estudei se não, não sei o que seria de mim, talvez nem um casamento tivesse conseguido.

Neste enunciado, os sentidos evidenciam que sua mobilidade social não se deu por meio de um casamento com um homem branco, mas por sua dedicação e empenho com práticas que permitiriamuma melhor profissionalização. Ela nunca deixou de privilegiar os estudos e isso se confirma em seu processo de desenvolvimento profissional no qual a professora procura por um curso de especialização quando percebe que formação acadêmica é, talvez, a via mais segura para o seu acesso às novidades, multiplicidade de escolhas e mudanças impostas pelo mundo líquido-moderno.

\section{CONCLUINDO}

Bauman (2005) afirma em seus estudos que, na atualidade de espaços fluidos, fica muito difícil saber se o futuro será de enchente ou seca,e que a melhor saída é preparar-se para as duas possibilidades. Parece que em relação às práticas identitárias, há também uma ambiguidade. Os sujeitos se veem em uma batalha constante entre discursos de segurança, conforto e aconchego da comunidade e discursos instáveis, perigosos, estranhos, propostos nas práticas de liberdade, presentes em alguns discursos de verdade, cujos efeitos são evidenciados em um dos gumes da faca empunhada no jogo de identidades. 
Esse jogo parece estar presente na pesquisa realizada e nos permite apresentar alguns resultados neste artigo acerca da construção dos projetos identitários da professora Sol, travados em uma batalha contra os intuitos de segregação e exclusão. Assim, ao examinarmos algumas sequências discursivas que compõem a narrativa da docente, notamos que algumas marcas identitárias eram construídas a partir de um modo contestador de práticas circulantes em algumas esferas socais e entre sujeitos que faziam parte da vida pessoal, profissional e afetiva de Sol. Os discursos desses sujeitos tentavam produzir efeitos de segurança, mas em troca havia um preço a pagar: Sol deveria abrir mão da liberdade de escolha, da autonomia, da invenção de outras identidades.

Mas, Sol percebe que não há apenas este caminho e que a faca que compõe a identidade possui dois gumes. Um deles parece evidenciar exatamente o gume dos discursos dominadores, que apontam a negação do acesso às escolhas identitárias e da manifestação de preferências, a opressão e imposição por outros de identidades já escolhidas previamente e que estereotipam, humilham, estigmatizam os sujeitos tentando assujeitá-los, ao privá-los da liberdade de escolha. O outro gume da faca revela os posicionamentos discursivos assumidos por Sol e que refletem os seus anseios por liberdade, por outra identidade. Liberdade que não se traduz em ausência de determinismos, de confrontação, pois a liberdade não é algo que se tenha ou se atinja de uma única vez. Liberdade é a "condição de um 'trabalho indefinido' de pensamento, ação e autoinvenção” (RAJCHMAN, 1993, p. 129).

Para tentar demonstrar esse processo retomamos à narrativa de Sol quando ela enuncia:

É bom saber que as pessoas estão discutindo sobre nossa raça também é bom levar isso pra escola, ninguém conversa abertamente sobre essas questões raciais, é como se tudo tivesse muito bom.

Esse posicionamento de Sol demonstra que, embora ela não possa ter segurança e liberdade na justa medida, isto não a impede de realizar escolhas, fazer novas tentativas, aventurar-se em outros jogos de verdade, uma vez que a identidade deve ser compreendida como diferença, singularidade, experiência, invenção e outra possibilidade de brandir a faca. 


\section{REFERÊNCIAS}

BAUMAN, Z. Comunidade: a busca por segurança no mundo atual. Rio de Janeiro: Jorge Zahar, 2003.

2005. . Identidade: entrevista a Benedetto Vecchi. Rio de Janeiro: Jorge Zahar, - A arte da vida. Rio de Janeiro: Jorge Zahar, 2009.

BERQUÓ, E. Demografia da desigualdade. Novos Estudos Cebrap, n. 21, p. 7485,1988 .

. Sexualidade e demografia. In: LOYOLA, M (Org.). A sexualidade nas ciências humanas. Rio de Janeiro: UERJ, 1998.

CELANI, M. A.A. Afinal, o que é Linguística Aplicada? In: PASCHOAL, M. S. Z.; CELANI, M.A.A. (Orgs.). Linguística Aplicada: da aplicação da Linguística à Linguística Transdisciplinar. São Paulo: Educ, 1992. p. 15-23.

DUBAR, C. A socialização: Construção das identidades sociais e profissionais. Porto: Porto Editora, 1997.

FOUCAULT, M. Tecnologías del yo. In: Tecnologias del yo y otros textos afines. Barcelona: Paidós Ibérica, 1990.

. Microfísica do poder. 18. ed. Rio de Janeiro: Edições Graal,2003. - A ética do cuidado de si como prática de liberdade. In: . Ética, sexualidade, política. Rio de Janeiro: Forense Universitária, 2004a. . A ordem do discurso. 10. ed. São Paulo: Edições Loyola, 2004b.

FRY, P. O que a Cinderela negra tem a dizer sobre a 'política racial' no Brasil. Revista USP 28, dezembro, p. 122-135, 1995/96.

GILROY, P. Entre campos: nações, cultura e o fascínio da raça. São Paulo: Annablume, 2007.

MOITA LOPES, L. P. da. Oficina de linguística aplicada: a natureza social e educacional dos processos de ensino/aprendizagem de línguas. Campinas-SP: Mercado de Letras, 1996. . Linguística aplicada e vida contemporânea: problematização dos construtos que têm orientado a pesquisa. In: INdisciplinar. São Paulo: Parábola Editorial, 2006. . Por uma linguística aplicada 
Da aplicação da linguística à Linguística Aplicada indisciplinar. In: PEREIRA, R. C.; ROCCA. P. (Org.). Linguistica aplicada: um caminho com diferentes acessos. São Paulo: Contexto, 2009.

MOUTINHO, L. Razão, "cor” e desejo: uma análise comparativa sobre relacionamentos afetivo-sexuais "inter-raciais" no Brasil e na África do Sul. São Paulo: Unesp, 2004.

ORLANDI, E. P. Introducão às ciências da linguagem. Discurso e textualidade. Campinas (SP): Pontes, 2006.

PÊCHEUX, M. Semântica e discurso: uma crítica à afirmação do óbvio. Campinas: Unicamp, 1988.

PENNYCOOK, A.Uma linguística aplicada transgressiva. In: MOITA LOPES, L. P. (Org.) Por uma linguística aplicada indisciplinar. São Paulo: Parábola, 2006. p. 67-84.

RAJCHMAN, J. Eros e verdade: Lacan, Foucault e a questão da ética. Rio de janeiro: Jorge Zahar, 1993.

SANTOS, H. A busca de um caminho para o Brasil: a trilha do ciclo vicioso. São Paulo: SENAC São Paulo, 2003.

SIGNORINI, I. Os estudos sobre identidade e lingua(gem) em Linguística Aplicada. In: BARROS, K. S. M.. (Org.). Produção textual: interação, processamento, variação. Natal: Editora da UFRN, 1999. p. 63-67.

SILVA, N. do V. Distância social e casamento inter-racial no Brasil. Estudos Afro-Asiáticos, n. 14, p. 54-83, 1987.

Recebido em: 24/10/11. Aprovado em: 20/08/12.

Title: From identity battles to freedom practices: a black teacher's life stories

Authors: Marluce Pereira da Silva; Carmen Brunelli de Moura; Francisca Maria de Souza Ramos Lopes

Abstract: The present article analyses the production of meanings in the self-narrative of a black teacher while she builds her identity projects concerning her academic and professional trajectories and her affective/conjugal arrangements in face to her racial belonging. The guiding question of the discussion: in what point the teacher assumes a discursive positioning that reflects the interaction between her wishes of individual freedom and/or the safety offered by the community (BAUMAN, 2003). Foucault's theories are used as analytical tools, articulated to ethnic-racial studies, identity and notions of French Discourse Analysis. The conclusion is that the teacher, in her auto-biographical scripts, has gathered strategies witch translate battles that she waged when building her identity projects, as far as she made a life story marked by effects that contradict speeches that history has reserved to blacks.

Keywords: Identity projects. Practices of freedom. Black teacher. 
Titulo: De las batallas identitarias a las prácticas de libertad: historias de vida de una profesora negra Autores: Marluce Pereira da Silva; Carmen Brunelli de Moura; Francisca Maria de Souza Ramos Lopes

Resumen: En este artículo, se analisa la producción de sentidos en la autonarrativa de una profesora negra al construir sus proyectos identitarios concernientes a la trayectoria escolar y profesional, a los arreglos afectivo-conyugales devido a su pertenencia racial. Se define como cuestión de rumbo de la discusión: en que medida la docente asume posiciones discursivas que reflejan la interacción entre sus ansias por la libertad individual y/o la seguridad que la comunidad (BAUMAN, 2003) ofrece. Se utilizan como dispositivos analíticos las teorizaciones foucaultianas, encadenadas a estudios étnico-raciales de identidade y nociones del Análisis del Discurso Francés. Se concluye que la docente, en sus guiones autobiográficos, se sirve de estrategias que traducen batallas por ella libradas al construir sus proyectos identitarios, a medida que instituye una historia de vida traducida por efectos que contradicen discursos que la bistoria reservó a negros/as.

Palabras-clave: Proyectos identitarios. Prácticas de libertad. Profesora negra.

SILVA; MOURA; LOPES - Das batalhas identitárias às práticas de liberdade... 